\title{
Welding Consumable Development for a Cryogenic (4 K) Application
}

\author{
Research led to the development of a nitrogen- and manganese-modified, high- \\ nickel stainless steel alloy for a demanding cryogenic magnet application
}

\author{
BY S. F. KANE, A. L. FARLAND, T. A. SIEWERT AND C. N. MCCOWAN
}

\begin{abstract}
This paper summarizes the development and qualification of an appropriate welding consumable for a demanding cryogenic magnet application. It begins with a review of the research conducted on cryogenic fracture toughness of wrought and welded austenitic stainless steels. This research shows that certain elements of the composition have a powerful elfect upon the steel's fracture toughness at $4 \mathrm{~K}$. In particular, the higher oxygen content in the weld manifests itself as inclusions, which have a severe detrimental effect upon the fracture toughness. This one factor accounts for most of the difference in toughness between wrought and weld materials of similar composition, and is a function of the weld process. Also, welds enriched with manganese and nickel have demonstrated improved fracture toughness. These discoveries were combined in the development of a nitrogen- and manganese-modified, high-nickel stainless-steel alloy. It produced gas metal arc welds with superior cryogenic mechanical properties (yield strength near $900 \mathrm{MPa}$ at $4 \mathrm{~K}$ and a Charpy $\mathrm{V}$-notch impact energy near 140 I at $76 \mathrm{~K}$ ) when the procedures were modified to reduce the oxygen content.
\end{abstract}

\section{Background}

In 1983 and in 1989, the nuclear physics community prepared long range plans for the U.S. Department of Energy and the National Science Foundation. In both years, they identified the Relativistic Heavy lon Collider (RHIC) as the highest priority for facility construction. In response, the U.S. Congress appropriated the first construction funds for the RHIC

S. F. KANE and A. L. Farland are with Brookhaven National Laboratory, Upton, N.Y., and T. A. SIEWERT and C. N. MCCOWAN are with National institute of Standards and Technology, Boulder, Calo. in fiscal year 1991. The construction of the RHIC, at the Brookhaven National Laboratory ( $B N L$ ), will provide the United States with a world-class facility with a potential for unique discoveries. Specifically, the RHIC will be able to create matter at extremely high temperatures and densities - so extreme that scientists hope to ohserve phenomena that have not occurred in the natural universe since the original "Big Bang." These experiments cannot be conducted at existing high-energy accelerator facilities.

In the RHIC, two beams of heavy ions will speed in opposite directions inside a pair of rings in a tunnel almost $3.9 \mathrm{~km}$ in circumference. The beams will be bent and focused by more than 1700 superconducting magnets. The material and magnetic property requirements (material strength to resist the mechanical loads and the fracture toughness requirements at $4 \mathrm{~K}$ ) of these magnets are very demanding. This paper concentrates on the weld design and materials to meet the design requirements of the superconducting magnet structures.

\section{BNI. Magnet Design Requirements}

A superconducting magnet has the same basic structure as a traditional electromagnet - an iron core wound with an

\section{KEY WORDS}

Cryogenic
Ferrite
Fracture Toughness
Gas Metal Arc Welding
Inclusions
Nitrogen
Stainless Steel
Strength

\section{Cryogenic}

Ferrite

Fracture Toughness

Gas Metal Arc Welding

Inclusions

Stainless Steel

Strength electrical cable. In the case of niobiumtin superconducting magnets, the electrical cable is superconducting and must he maintained at a temperature of less than $4.6 \mathrm{~K}$. The cable and iron core are enclosed within a cryogenic pressure vessel to provide this cooling. The U.S. Department of Energy requires that all pressure vessels at its facilities comply with the American Society of Mechanical Engineers (ASME) Boiler and Pressure Vessel Code. These requirements, coupled with the cryogenic system design and manufacturing cost parameters, require a weld yield strength of $900 \mathrm{MPa}$ for the 4.8-mm-thick stainless steel magnet shells, a ferrite number (FN) less than 3 for weld processes other than gas tungsten arc welding (GTAW) and gas metal arc welding (GMAW) and a lateral expansion greater than $0.38 \mathrm{~mm}$ for a Charpy V-notch (CVN) impact test at the operating temperature. ASME Code paragraph UG-84 requires impact testing for applications operating at temperatures below $19 \mathrm{~K}$, where the RHIC pressure vessels will be operating, yet impact testing at $4 \mathrm{~K}$ is complicated by the low heat capacity of materials at this temperature. The ASME Code (originally developed for applications near room temperature or above) had been applied to cryogenic temperatures without adjusting for the changes in the physics of heat flow and deformation. The standard Charpy impact test prescribed by the American Society for Testing and Materials (ASTM) Standard E 23 becomes questionable at extreme cryogenic temperatures. Recent studies show that a specimen cannot be transferred from a $4 \mathrm{~K}$ cooling bath to the test machine quick enough to avoid exceeding the test temperature by a large margin (Ref. 1). Furthermore, the adiabatic heating associated with deformation has such an influence on all materials at this temperature that the deformation preceding fracture often in- 


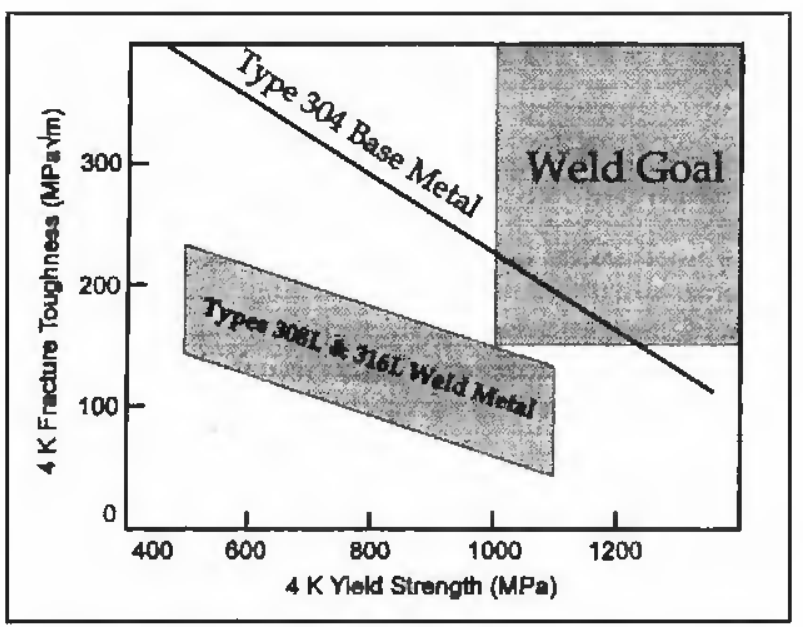

Fig. 1-Comparison of the relationships for weld and base metal strength-toughness.

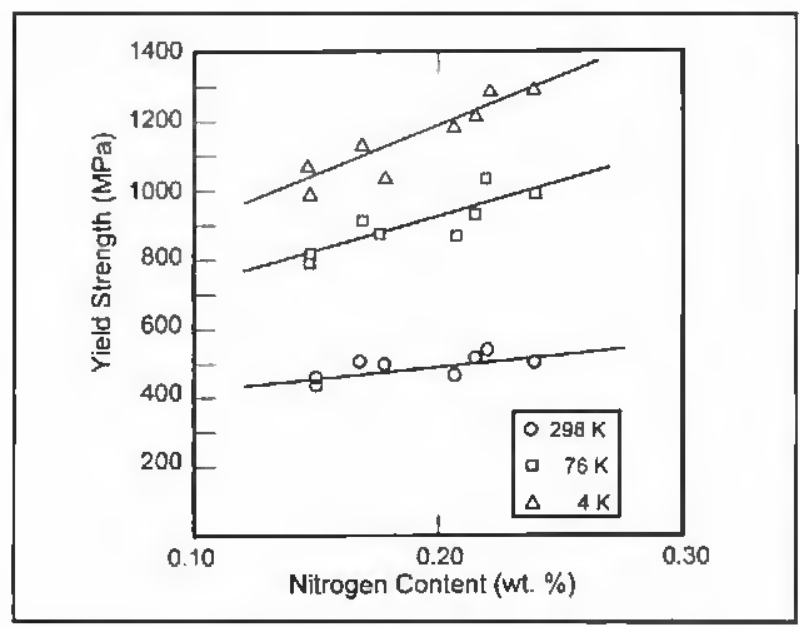

Fig. 2 - Vield strength vs, nitrogen content for Type $316 L$ N welds. creases the specimen temperature by 70 Kor more. This means the specimen temperature might far exceed the test temperature during fracture even while using innovative techniques to keep the specimen cool until the insiant of fracture (such as cooling the specimen while it is already sitting on the impact machine anvils). This testing may provide acceptable data for projectile impact tests, but cannot provide valid data for a large structure at $4 \mathrm{~K}$. What we wanted was a large cryogenic structure with acceptable fracture toughness, not simply good impact data. The solution to this dilemma is engineered welds.

\section{Engineered Welds}

Fracture mechanics calculations conducted for several cases showed the fracture toughness $\left(K_{1 c}\right)$ of the magnet should be at least $68 \mathrm{MPa} \sqrt{\mathrm{m}}$ at $4 \mathrm{~K}$. While this fraciure toughness requirement appears relatively easy to achieve, it forms the minimum design requirement. Current data indicate a one-sigma scatter band of $\pm 44 \mathrm{MPa} V \mathrm{~m}$ (Ref. 2). This indicales that the nominal fracture toughness value must be at least $156 \mathrm{MPa} / \mathrm{m}$ to guarantee that a $95 \%$ confidence level is achieved. This requirement places the necessary fracture toughness at the upper boundary for commercially available weld metal, as shown in Fig. 1 (Ref. 2).

One complexity in designing for fracture resistance is that many published reports, including the ASME Code, specify qualitative CVN impact requirements as absorbed energy, in joules, or lateral expansion, in millimeters, while strict fracture-mechanical calculations use quantitative fracture toughness data, in MPa $\sqrt{ }$. These are significantly different ap- proaches and we wanted to be certain that we fulfilled both needs. Therefore, we generated both types of data for our welds, then compared our data to both types of requirements.

Canventiana! wisdom says the weld should match the composition of the base material as much as possible. This general rule is very often useful in helping designers avoid problems due to differences in thermal expansion (residual stress and distortion), corrosion polentials and differences in strength. This structure will not be subject to a severely corrosive environment, but the other problems could be important, so we favored a matching composition. To guide our selection of the electrode composition, we found several studies of materials and joining processes for specific cryogenic magnel structures that provided very practical advice (Refs. 3, 4). In particular, Goodwin's 1985 paper (Ref. 3) describes the construction of large magnet cases of Type 316LN stainless steel (the large coil programi) for $4 \mathrm{~K}$ service. Goodwin found an extremely wicle range in reported mechanical properties for candidate welding consumables and described how they qualified electrodes that met their property requirements. For the RHIC, we wanted a margin between the requirements and typical propertics that was wider than those listed in this study (for greater reliability). Therefore, we broadened our scope to include alternative compositions, especially compositions developed or evaluated since these reports, but kept the potential strength and thermal expansion differences in mind when evaluating their suitability.

Other published studies of material properties provide broader guidance on the effect of various elements and on the selection of a material to meet a set of mechanical properties (Rers. 5-18). Reference 14 shows that the strength of austenitic stainless stecl at cryogenic temperature is controlied primarily by the nitrogen content. Predictive equations for weld strength have a relatively small scatter (standard deviation near $50 \mathrm{MPa}$, or about $6 \%$ for this application\}, and the range of strength data spans the 900-MPa goal of the RHIC. Figure 1 shows data for strength vs. toughness for Types 308L and 316L stainless steel compositions. Unfortunately, it shows as the strength increases (through nitrogen ad- 


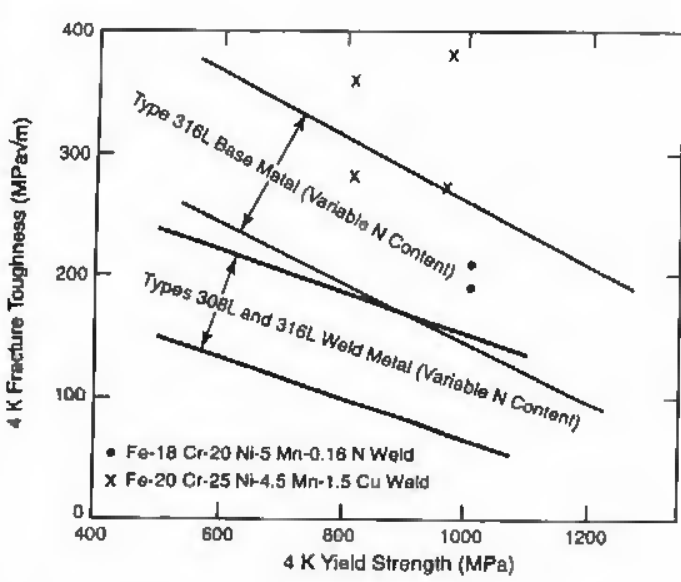

Fig. 4 - Fracture toughness vs. yield strength.
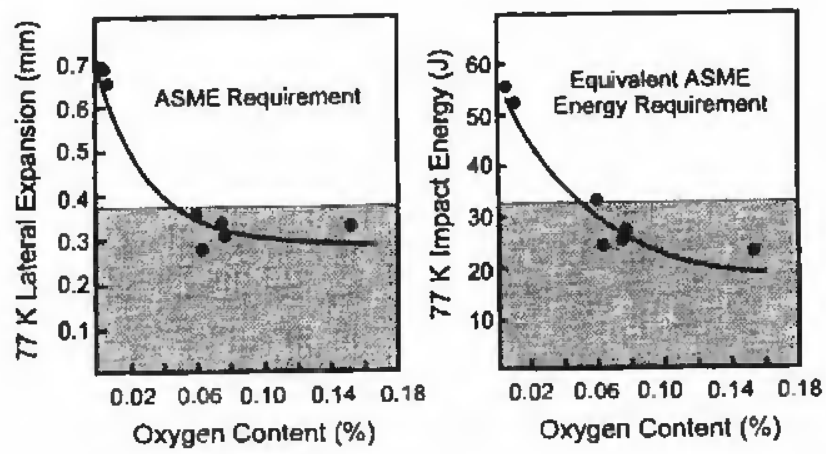

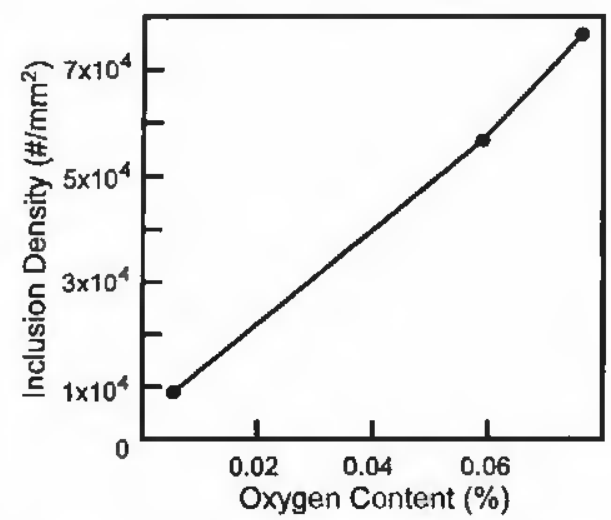

Fig. 6 - Linear relationship between inclusion density and oxygen content (Ref. 6).

ditions), the toughness decreases, so we were concerned about our ability to meet both the strength and the toughness requirements simultaneously. Figure 1 also shows the welds fail short of the base metal propertics. This was of concern to the designers because welds usually have an uneven surface profile and contain high residual stresses that can grow still larger when cooled to cryogenic temperatures. The combination of lower toughness, surface roughness and residual stresses could make the welds a critical fracture path during unexpected tensile overload or propagation of fatigue cracks. We were looking for welds that could match both the strength and toughness of the $304 \mathrm{~L}$ base material.

\section{Factors Affecting Cryogenic Strength and Toughness in Weld Metal}

Weld toughness is affected by many factors. One well-known metallurgical factor causing low toughness in weld metal is precipitates, such as carbides, nitrides and intermetallic compounds. The presence of delta ferrite and nonmetallic inclusions are also well-known detractors of toughness. Typical compositions (Types 308 and 316) used for cryogenic stainless welds generally fall about $40 \%$ below base metals in their $\sigma_{y}$ vs. K Ke performance (see also Fig. 1) (Ref. 2).

\section{Ferrite}

Delta ferrite is a residual phase present in some stainless steel welds that solidifics in a primary ferrite mode. Residual ferrite in small quantities is normally desirable in stainless steel welds because it inhibits the formation of compounds with low melting points (such as FeS and FeP) that promote hot cracking in fully austenitic alloys. However, ferrite should be minimized for best toughness in cryogenic service. Therefore, welding alloys for cryogenic service are either ferrite-free or very low in ferrite. The ferrite-free alloys are produced with very strict controls on the impurity contents that promote hot cracking. Also, welds with a FN greater than 7 show relatively low toughness, but welds with a lower FN are scattered within the one-sigma scatter band of \pm 44 $\mathrm{MPa}$ in Fig. 1. Thus, ferrite should be reduced to the lowest level consistent with cracking resistance.

Previous data from the National Institute of Standards and Technology (NIST) in Fig. 1 show an inverse relationship between yield strength and fracture tough- ness (Ref. 5). Test data available to date indicate eliminating delta territe, avoiding chromium carbides and reducing the width of columnar grains may increase the strength-toughness characteristics of welds. These actions will raise the trend line of the weld strength-toughness characteristics closer to that of wrought stainless steel.

Other research establishes that a Charpy absorbed energy of at least $32 \mathrm{~J}$ is necessary to meet the ASME minimum lateral expansion of $0.015 \mathrm{in} .(0.38 \mathrm{~mm})$ (Ref. 6). Reference 7 lists the following equation for $76 \mathrm{~K} \mathrm{CVN}$ impact energy as a function of $\mathrm{FN}$, calculated from the Schaeffler diagram (ferrite potential if negative), carbon content and nickel content:

$$
C V N(J)=19-1.4 F N-890 C 2+1.4 \mathrm{Ni}
$$

Of course, $\mathrm{FN}$ is determined by the composition, including $\mathrm{C}$ and $\mathrm{Ni}$, so this equation should be used cautiously. However, it does indicate that toughness is increased as $\mathrm{Ni}$ is increased, as $\mathrm{FN}$ is decreased and as $C$ is decreased. Quantitatively, it suggests that a CVN of 32 J requires a nickel content of no less than $11 \mathrm{wt}-\%$, if the $\mathrm{C}$ were restricted to 0.05 $w t-\%$ and the FN was zero. To have a reasonable safety factor, the $\mathrm{Ni}$ would have to be substantialjy higher.

\section{Nitrogen}

The strengthening characteristics of nitrogen become more pronounced at lower temperatures. Figure 2 shows how the yield strength of $316 \mathrm{~L}$ welds increases with increasing nitrogen content (Ref. 7). Yield strength at $0.20 w t-\% \mathrm{~N}$ increases by a factor of 2 as temperature is decreased from 298 to $76 \mathrm{~K}$, and in- 


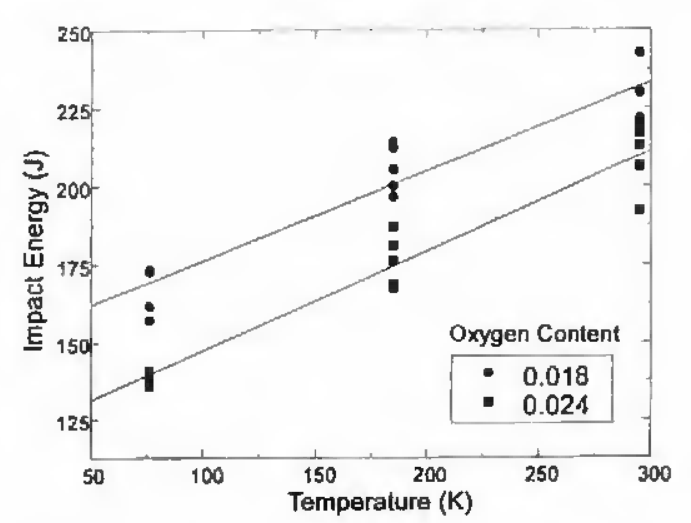

Fig. $7-C V N$ impact energy.

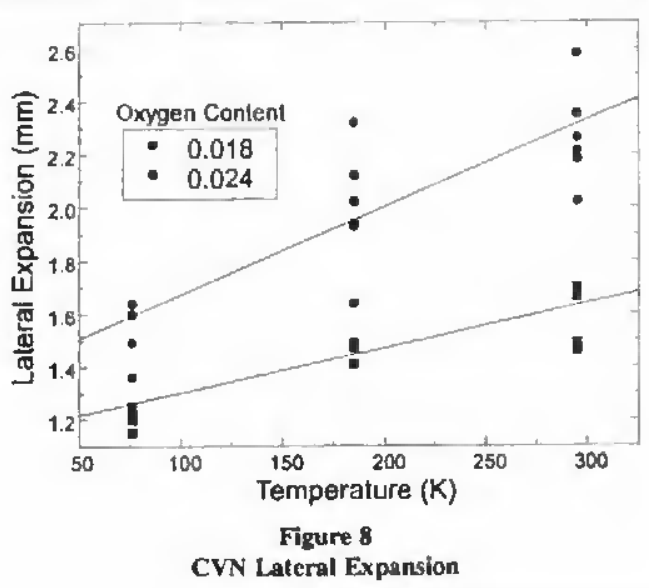

Fig. 8-CVN lateral expansion. creases by a factor of 2.5 when the temperature is decreased to $4 \mathrm{~K}$. Studies also show that increasing the nitrogen from the typical weld nitrogen content of $0.05 \%$ to $0.20 \%$ yields a threcfold increase in strength when cooled to $4 \mathrm{~K}$.

Nitrogen cannot be added without limit. The upper limit is determined by the solubility of nitrogen in the microstructure. Weld porosity uccurs above this limit. The solubility limit is a function of the composition, with certain elements (such as manganese) serving to increase the limit (Ref. 8). Manganese at a concentration above the 1.5 wt- $\%$ typical for austenitic stainless steels was added to provide greater protection from porosity formation and to act as a solid solution strengthener.

\section{Nickel}

Nickel also has a significant, though nonlinear, effect on toughness. Figure 3 shows that increasing nickel from 10 to $20 \%$ in the welds provides the greatest improvement in toughness. Thus, a weld with more than $20 \%$ nickel should exhibit the greatest attainable toughness for an austenitic stainless steel. Workers at NIST perfurmed work to determine an optimum weld material for $316 \mathrm{LN}$, which is a popular base material for demanding cryogenic applications (Ref. 7). Two commercially available compositions $118 \mathrm{Cr}-20 \mathrm{Ni}-5 \mathrm{Mn}-0.16 \mathrm{~N}$ and $20 \mathrm{Cr}-25 \mathrm{Ni}-4.5 \mathrm{Mo}$ ) were evaluated using GMAW. Shielding gases were mare inert than nurmal to reduce oxygen content, and the gas used for the $20 \mathrm{Cr}-2 \mathrm{SNi}$ 4.5Mo electrode was augmented with nitrogen to increase the nitrogen content of the weld metal. Figure 4 shows the strength was comparable to that of $316 \mathrm{LN}$ hase metal and the fracture toughness was equal to or greater than that of the $316 \mathrm{LN}$ base metal. This toughness clearly exceeds the toughness achievable with 308- and 316-based welding compositions and standard welding procedures.

Other research shows that higher nickel contents improve the toughness in two ways: nickel reduces the ferrite content of the weld metal (a magnetic mictrostructural phase and more brittle than austenite), and nickel additions increase the toughness in fully austenitic compositions (Refs. 9-12). Figure 3 shows how additions of nickel to stainless steel alloys generally increase the toughness, at least up to $20 \mathrm{wt}-\%$. A secondary benefit is that nickel stabilizes austenitic structures against the formation of martensite (another magnetic phase) during deformation. The two references on the fabrication of the cryogenic magnet structures mentioned their search for these magnetic phases during qualification and control of the welding procedure (Refs. 3, 4).

\section{Tramp Elements}

Fully austenitic compositions may be subject to hot cracks, which are ruptures that form in the hot weld during solidification. Studies show this tendency can be controlled by careful control of "tramp" elements, phosphorus and sulfur, that produce a low-melting-paint eutectic (Ref. 3). This problem is evident in electrode specifications where cracksensitive compositions can be available in a special grade with stricter limits on the elements that promote hot cracking. Sometimes the fully austenitic grades can be made less sensitive to cracking by adding clements such as manganese, copper or carbon that change the solidification structure. These elements may change the shape of the solidification front or change the amount of terminal eutectic between adjacent dendrites.

\section{Oxygen}

Because of its reactivity, free oxygen is not found in the weld. Instead, it combines with other elements to form oxide inclusions. These inclusions have diameters near $1 \mu \mathrm{m}$ and are spherical because they form in the liquid above the soliditication temperature. As the weld cools, these inclusions are entrained in the solid and have little effect on mechanical properties until the weld is deformed. Inclusions are harder than the surrounding metal matrix and serve as impediments to dislocation motion during deformation. As a result, substantial stresses form in the vicinity of oxide inclusions, causing voids to initiate. These voids then link hy void coalescence, leading to final fracture of the material. Since the voids nucleate at inclusions, reduction in the density and size of inclusions reduces the number of voids that form and is an obvious step in increasing the toughness of a weld. Stainless steel welds usually have lower toughness than wrought material. The primary difference between weld material and wrought material is the amounts of inclusions and ferrite. Welds will contain more inclusions because of the imperfect gas shiclding of the metal while malten. Studies have shown that correlation of toughness with inclusion spacing is similar for wrought material, which suggests that the differences in fracture toughness can primarily be attributed to this one factor (Refs. 14, 15).

Research on the effects of the welding process and shielding gas un turughness has been conducted using $308,308 \mathrm{~L}$ and $316 \mathrm{~L}$ filler metal; GTAW with $100 \%$ 
Table 1 - Effect of Oxygen Content on Inclusion Density and Yield 5trength

\begin{tabular}{|c|c|c|c|}
\hline $\begin{array}{l}\sigma_{y} \\
(\mathrm{MPa})\end{array}$ & $\begin{array}{l}\text { E1 } \\
(\%)\end{array}$ & $\begin{array}{l}\mathrm{RA} \\
(\%)\end{array}$ & $\begin{array}{c}\mathrm{K}_{\mathrm{Ic}} \\
(\mathrm{MPa} / \mathrm{m})\end{array}$ \\
\hline 736 & 47.9 & 46.6 & 179 \\
\hline 747 & 22.3 & 23.7 & 150 \\
\hline 743 & 10.2 & 13.1 & 132 \\
\hline \multicolumn{4}{|c|}{$\begin{array}{l}\text { Table } 2 \text { - Electrode Specification } \\
\text { (Ref. 19) }\end{array}$} \\
\hline \multicolumn{2}{|c|}{ Element } & \multicolumn{2}{|c|}{ Range $(\%)$} \\
\hline \multicolumn{2}{|c|}{ Carbon } & \multicolumn{2}{|c|}{$0.02 \max$} \\
\hline \multicolumn{2}{|c|}{ Manganese } & \multicolumn{2}{|c|}{$7.0-7.2$} \\
\hline \multicolumn{2}{|c|}{ Silicon } & \multicolumn{2}{|c|}{$0.2-0.5$} \\
\hline \multicolumn{2}{|c|}{ Phosphorous } & \multicolumn{2}{|c|}{$\begin{array}{l}0.018 \text { max (desired } \\
\text { as low as possible) }\end{array}$} \\
\hline \multicolumn{2}{|l|}{ Sulfur } & \multicolumn{2}{|c|}{$\begin{array}{l}0.004 \text { max (desired } \\
\text { as low as possible) }\end{array}$} \\
\hline \multicolumn{2}{|c|}{ Chromium } & \multicolumn{2}{|c|}{$20.9-21.7$} \\
\hline \multicolumn{2}{|c|}{ Nickel } & \multicolumn{2}{|c|}{$24.75-25.25$} \\
\hline \multicolumn{2}{|c|}{ Molybdenum } & \multicolumn{2}{|c|}{$4.75-5.25$} \\
\hline \multicolumn{2}{|c|}{ Copper } & \multicolumn{2}{|c|}{$1.25-1.75$} \\
\hline \multicolumn{2}{|c|}{ Nitrogen } & \multicolumn{2}{|c|}{$0.17-0.21$} \\
\hline \multicolumn{2}{|c|}{ Oxygen } & \multicolumn{2}{|c|}{$\begin{array}{l}0.015 \text { max (desired } \\
\text { as low as possible) }\end{array}$} \\
\hline \multicolumn{2}{|c|}{ Other } & \multicolumn{2}{|c|}{$<0.50$} \\
\hline \multicolumn{2}{|l|}{ Iron } & \multicolumn{2}{|c|}{ Remainder } \\
\hline
\end{tabular}

argon shiclding or GMAW with $\mathrm{Ar} / 2 \%$ $\mathrm{O}_{2}$ and $\mathrm{Ar} / 5 \% \mathrm{O}_{2}$ (Ref. 6). The results are shown in Fig. 5. Most of the elements in the chemical composition of the Type $316 \mathrm{~L}$ weld metal were consistent for the different processes, but the oxygen content changed dramatically $(0.005-$ $0.076 \%$ ). The study found the lateral expansion properties would meet A5ME requirements at $173 \mathrm{~K}$, but only the GTA weld shielded with pure argon would meet the requirement at $77 \mathrm{~K}$.

The oxygen contents of the Type $308 / 308 \mathrm{~L}$ weld metal ranged from 0.007 to $0.15 \%$, and the weld metal properties were similarly affected by oxygen content, with steep declines in lateral expansion and impact energy. Impact properties began to stabilize when oxygen content reached $0.06 \%$ oxygen. Mechanical tests revealed a relationship between $\mathrm{FN}$ and oxygen content and the ability to meet the A5ME lateral expansion requirement. However, the low-oxygen GTA weld could meet the A5ME requirement easily, even with a relatively high FN, while the high-oxygcn-content welds could not meet the lateral expansion requirement, even with a $\mathrm{FN}$ of 5. This accounts for the A5ME recommendation for a FN lower than 3 for weldments produced by processes other than GTAW and GMAW (Ref. 6).

Kim's study also found an excellent correlation between lateral expansion (LE) and impact energy at 173 and $76 \mathrm{~K}$ (Ref. 6). This relationship is described by the following equation: gen content; $1500 x$ ).

\begin{tabular}{ccc}
$\begin{array}{c}\text { Oxygen } \\
(w \mathrm{t}-\%)\end{array}$ & $\begin{array}{c}\text { Inclusion } \\
\left(\$ \times 10^{3} / \mathrm{mm}^{2}\right)\end{array}$ & $\begin{array}{c}\text { Inclusion Spacing } \\
(\mu \mathrm{m})\end{array}$ \\
0.004 & 19.3 & 7.0 \\
0.048 & 37.7 & 5.0 \\
0.072 & 55.2 & 4.3 \\
\hline
\end{tabular}

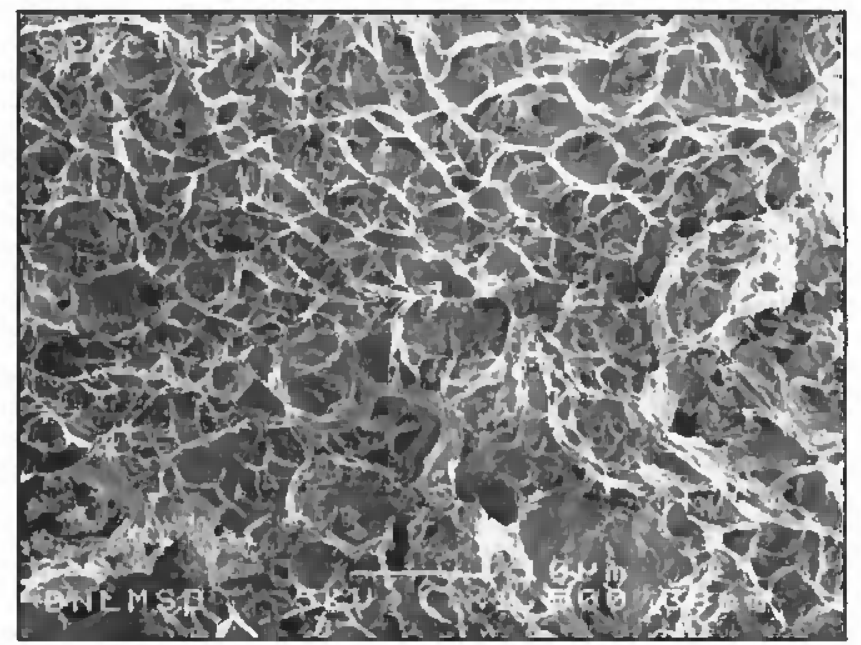

Fig. 9 - Fraclure surface of Charpy specimen al $76 \mathrm{~K} 10.024 \%$ oxy-

$\mathrm{LE}(\mathrm{mm})=0.012 \times \mathrm{C}_{\mathrm{v}}$ (Joule $)$

Thus, the ASME lateral expansion requirement of $0.38 \mathrm{~mm}$ is equivalent to an impact energy of $32 \mathrm{~J}(23.6 \mathrm{ft}-\mathrm{lb})$. Fractographic analysis of the $76 \mathrm{~K}$ Charpy $\checkmark$-notch specimens showed more brittle fracture of ferrite on the fracture surface of samples with decreased oxygen content. This is attributed to crack initiation and propagation for welds having retained delta ferrite and very low inclusion content. The fracture in this casc is morc likely to initiate in, and follow, the ferrite phase. The overall iracture process, however, still requires high energy because the ductile austenitic matrix prevents continuous brittle fracture in the weld. Fractures in welds with high oxygen content initiate by the formation of microvoids and propagate by $\mathrm{mi}$ crovoid coalescence. This proceeds so easily that the whole fracture occurs in a fully dimpled mode at low energy. Therefore, it is possible to increase impact toughness in low-oxygen welds by decreasing ferritc, but ferrite control would not be effective in high-oxygen welds because ferrite has a negligible role in the fracture process.

This effect also was studied by Whipple and Kotecki (Ref. 17), who produced a series of 316L welds using GTA, GMA and submerged arc welding ( $5 \mathrm{AW}$ ). The tough ness at $4 \mathrm{~K}$ was found to be inversely proportional to the inclusion content, with the highest toughness found in the GTA welds $(181 \mathrm{MPa} \cdot \sqrt{\mathrm{m}})$. Other research found the $K_{\mathrm{k}}$ of Type $316 \mathrm{~L}$ stainless steel weld composition increased significantly at $4 \mathrm{~K}$ when inclusion contents in GMA welds were decreased (Ref. 18). The study showed an increase in toughness of 18 $\mathrm{MPa} \cdot \sqrt{\mathrm{m}} / \mu \mathrm{m}$ in average inclusion spacing.

Siewert and McCowan tested specimens made by varying shielding gas composition over 304 plate with $316 \mathrm{~L}$ electrodes (Ref. 18). Material properties are shown in Table 1. Inclusion density had little effect on yield strength, which varied less than $4 \%$, but fracture toughness increased by $35 \%$ as the inclusion content decreased by $65 \%$. The wide scatter for toughness data of weld metals is attributed to the varying inclusion contents when several welding processes are used.

Finally, the inclusion density is linearly related to oxygen content, as shown in Fig. 6 (Refs. 6,15 ). This is useful because oxygen content can be determined much more quickly and economically using standard proccdures and equipment than inclusion density, for which standards have not yet been developed. Clearly, minimizing oxygen content, thus minimizing inclusion density, will ensure that a minimum toughness will be exceeded.

\section{Final Electrode Composition}

$8 y$ combining the desirable ranges for the various elcments listed above, we arrive at the following aim composition for our weld (and welding electrocle):

- 25 wt-\% nickel (to provide good toughness),

- 20 wt- $\%$ chromium (to develop the fully austenitic composition),

- 0.18 wt-\% nitrogen (to provide a yield strength of $900 \mathrm{MPa}$ at $4 \mathrm{~K}$ ),

- 7 wt-\% manganese (to increase the solubility of nitrogen, strengthen the weld and reduce the hot-cracking sensitivity),

$\downarrow 1.5$ wt-\% copper (to reduce the hotcracking sensitivity by modifying the solidification front substructure; copper is intentially added to other austenitic alloys such as ER320, ER320LR, ER383 and ER385 [Ref. 161),

- 5 wt-\% molybdenum (to strengthen the weld),

- 0.005 wt $\%$ upper limit on "tramp elements" phosphorus and sulfur (to re- 


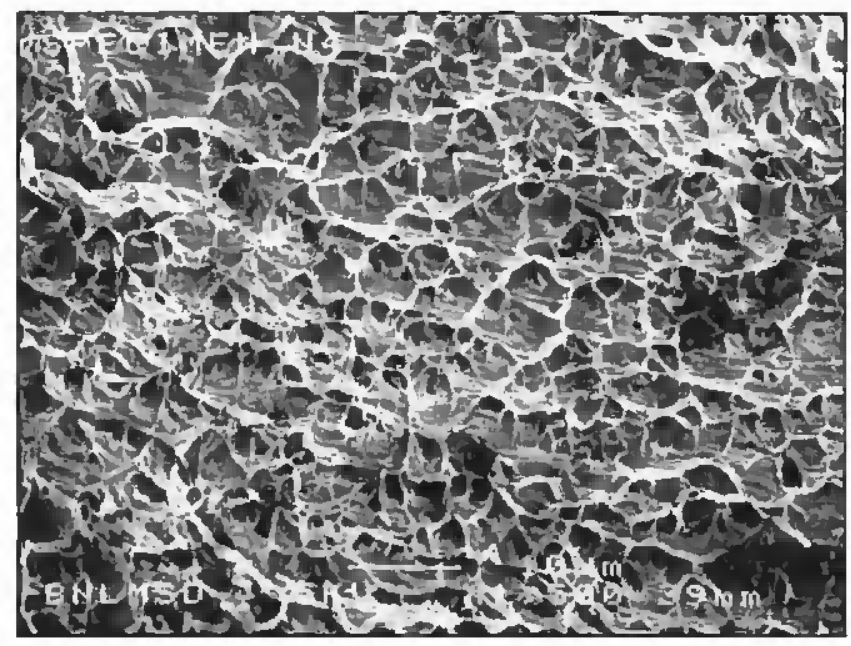

Fig. 10 - Fracture surface of Charpy specimen at $76 \mathrm{~K}(0.018 \%$ oxygen content; $1500 X)$.

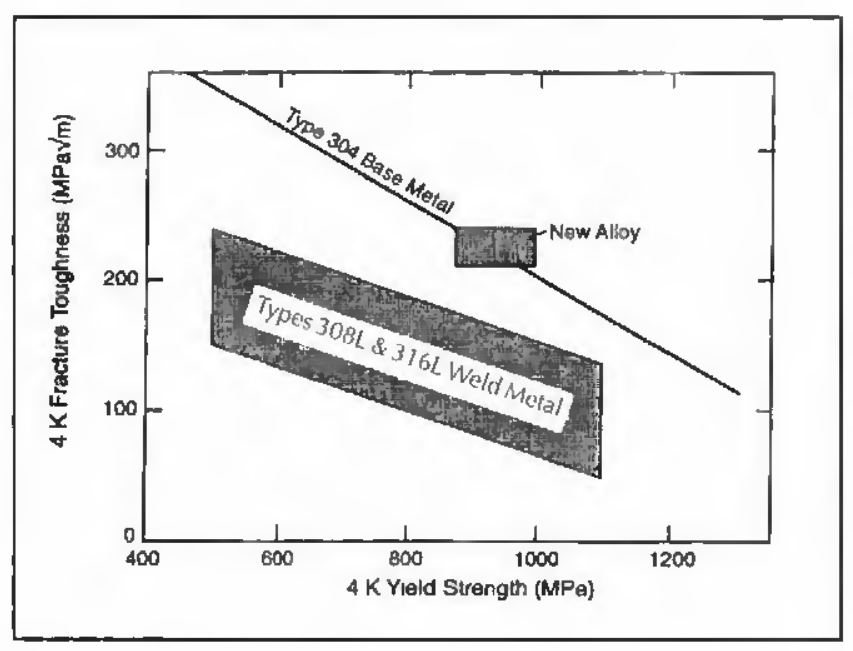

Fig. 11 - Test alloy mechanical properties. duce the hot-cracking sensitivity) and

- 0.02 wt-\% upper limit on oxygen (to produce higher toughness).

Working with electrode manufacturers, we adopted the composition specification detailed in Table 2. Because this composition does not match that of the Type 304L. base metal, we need to consider the potential problems of nonmatching compositions. This composition is fully austenitic, as is the base material, so they should have closely matched coefficients of thermal expansion, and so develop only minor residua! stresses. The strength has been matched, so there should be no problems with localized strain. The weld has a high nickel content, so it should have no ferrite and be very resistant to the formation of martensite under deformation at cryogenic temperatures. The low limits on phosphorous and sulfur should minimize the tendency for hot cracking, but we need to watch for poorer penetration due to a change in the weld pool convection.

\section{Process Selection}

The differences between weld materials and wrought materials are the inclusion and ferrite contents. Welds will have a higher inclusion content hecause of the imperfect shielding of the metal while molten. Therefore, choosing the welding process that produces the lowest inclusion content, or modifying the process to reduce inclusion content, is required to improve weld toughness. Welding processes such as laser, electron beam and GTA can produce welds with lower inclusion contents and with toughness at the upper side of the scatter band (Refs. 17, 20) - Fig. 1.

Initially, we considered a variety of welding processes - shielded metal arc (SMA), GTA, GMA and flux cored arc (FCA) - because they all are appropriate for base metals with a thickness near $5 \mathrm{~mm}$ and do not require special chambers, special alignment or expensive power sources. From this list, we eliminated SMAW because it is not amenable to automation and ranked GTAW lower than the others because it has a lower deposition rate.

The number of inclusions is a function of both the oxygen content of the welding electrode as manufactured and of the oxygen that is added during welding. Both sources of oxygen content must be controlled to produce the best toughness in the weld. We were unable to locate an FCAW electrode with a slag system that produced low inclusion contents, so this reduced our weld process choices to GMA and GTA welding.

GMAW is preferred for higher production rates, but the process might not produce adequate mechanical properties unless tightly controlled. Some of the newer, commercially available pulse power supplies provide excellent manual welding results. Other, older power sources are less flexible because their preset schedules are not applicable to the wide range of filler materials and gas compositions. BNL. selected a modern weld power source employing a proprietary, constant-current power supply with a patented, pulse-width-modulated, constant-voltage control. This feature provides the ability to optimize the pulsed-spray arc and process characteristics using a set of direct unit controls. The full range of parameter controls on this system is far more complicated than the typical single-knob systems, but the process is more suitable for automated operation. More precise control over the arc and other process characteristics yield a cleaner weld with more consistent composition and microstructure.

\section{Test Procedures}

\section{Materials and Weiding Details}

Workers at NIST ordered a small laboratory heat $(100 \mathrm{~kg})$ to evaluate the properties. After successful results with this laboratory heat, BNL ordered a production quantity and evaluated it in a similar manner. The chemical compositions used in this study, as received from the manufacturer, are shown in Table 3. The actual weld compositions varied from these heat compositions due to difution by the 304 plate material and by some losses during welding. The dilutions were estimated to be as high as $30 \%$ in the root pass and near the fusion boundaries and as low as 5\% near the center of the last pass. Small losses due to volatilization and oxidation are expected for the manganese, silicon and chromium. Still smaller changes are expected for the nickel and molybdenum. Little change is expected in the nitrogen level.

The testing was conducted in three increments. Workers at NIST determined the mechanical properties of the welds made with the first heat and the efiect of oxygen on the weld metal. Workers at BNL first evaluated the NIST heat to establish a baseline for material propertics, then evaluated their own heat to verify mechanical properties. All welds were deposited using the GMA process in single 60-deg V-grooves, as specified in AWS A5.4-81, on Type 304 base plates; $2.5 \mathrm{~mm}$ thick for all NIST testing, $12.7 \mathrm{~mm}$ 
Table 3 - Electrode Heat Compsitions

\begin{tabular}{lccccccccccc} 
& $\mathrm{C}$ & $\mathrm{Mn}$ & $\mathrm{Si}$ & $\mathrm{P}$ & $\mathrm{S}$ & $\mathrm{Cr}$ & $\mathrm{Ni}$ & $\mathrm{M}$ & $\mathrm{Cu}$ & $\mathrm{N}$ & $\mathrm{O}$ \\
NIST & 0.013 & 7.22 & 0.39 & $<0.005$ & 0.0019 & 21.36 & 25.16 & 5.16 & 1.61 & 0.19 & 0.0048 \\
BNL & 0.013 & 7.2 & 0.4 & 0.015 & $<0.001$ & 21.3 & 24.97 & 4.86 & 1.25 & 0.19 & 0.002 \\
\hline
\end{tabular}

Table 4 - Test Weld Parameters

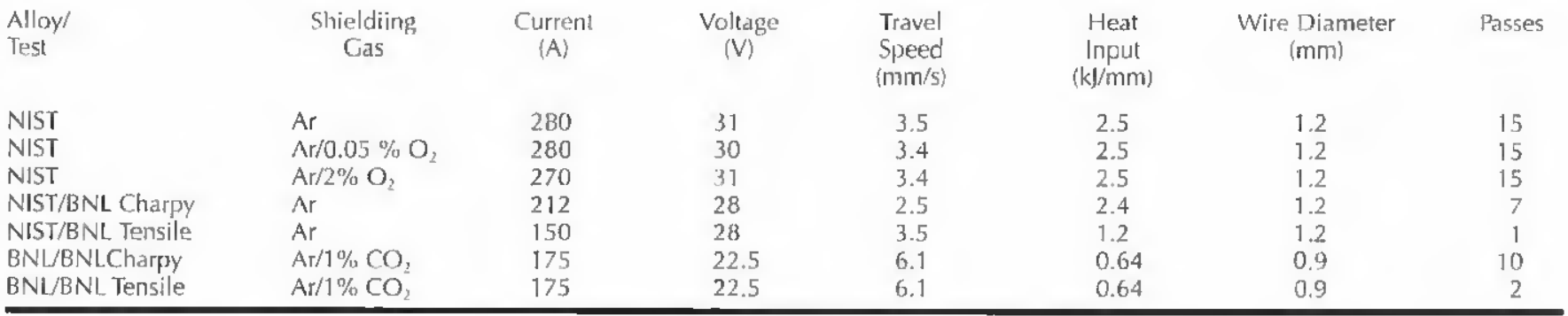

for BNL Charpy testing and $4.8 \mathrm{~mm}$ thick for BNL tensile testing. A $1-\mathrm{mm}$ rout opening was used for the BNL tensile tests, and all other weids used a $12-\mathrm{mm}$ root opening. The interpass temperalure was $175^{\circ} \mathrm{C}\left(372.6^{\circ} \mathrm{F}\right)$ and no postweld heat treatments were performed. Other test weld parameters are listed in Table 4. No compositional analysis was performed on the final welds, but microstructural analysis of polished sections showed the fusion zone to be fully austenitic. This supports the assumption that the weld should remain fully austenitic even after dilution by the base plate during welding. Further, this composition is far away from regions with a different solidification mode or phase structure, so typical levels of dilution are expected to have little effect on the mechanical properties.

One of the purposes of the NIST testing was to evaluate the effects of inclusions. Within each series of NIST welds, systematic variations in the volume fraction of weld metal inclusions were achieved by varying the oxygen potential of the shielding gas. For these welds, the heat input was kept fairly constant at $2.5 \mathrm{~kJ} / \mathrm{mm}$ to obtain a relatively equal distribution of inclusion sizes. These welds were performed manually, with a shielding gas flow rate of $16.5 \mathrm{~L} / \mathrm{min}$. The initial BNL test welds using the NIST alloy were performed manually, using laboratory grade $(99.999 \%$ ) argon flowing at $16 \mathrm{~L} / \mathrm{min}$. Past experiences with commercial-grade argon led BNL to adopt laboratory grade for all welding. However, government rates for this grade remain belaw the nongovernment cost for commercial grade, resulting in a negligible cost impact. The BNL test welds using the BNL alloy were performed automatically using pulsed
GMAW. Shielding gas was laboratorygrade argon with $1 \%$ carbon dioxide, flowing at $16.5 \mathrm{~L} / \mathrm{min}$. The addition of carbon dioxide improved the arc stability significantly over the laboratory welds made with pure argon.

\section{Mechanical Testing}

From each NIST weld, one all-weldmetal uniaxial tensile specimen $(6.25 \mathrm{-mm}$ diameter, 25.4-mm gauge length) and two through-thickness compact tension specimens (CTS) were machined for testing in liquid helium (4 K). The CTS were tested in accordance with ASTM Standard E 81389 , using the single-specimen compliance method, while the all-weld-meta! tensile specimens were strained at a constant cross-head specd of $0.5 \mathrm{~mm} / \mathrm{min}$. The BNL magnet design employs $4.8-\mathrm{mm}$ thick shells, hence they performed additional tests on the final structural form. Transverse tensile test specimens werc machined from 4.8-mm-thick welded test plates with the weld centered within the gauge length, and were strained at a constant cross-head speed of $10 \mathrm{~mm} / \mathrm{min}$. Charpy impact testing was performed in accordance with ASTM Standard E 23-B8 with full-size $V$-notch specimens using a machine with a $U$-shaped pendulum and 325-J capacity.

The ASME Boiler and Pressure Vessel Code requires testing of the mechanical properties at the service conditions. Tensile testing at $4 \mathrm{~K}$ requires special equipment, but the procedures are well documented. We followed the standard procedure of ASTM E 1450 for chilling the specimens, adding liquid helium until they are submerged and performing the test after reaching thermal equilibrium. Similarly, the Charpy specimens were cooled to $76 \mathrm{~K}$ using liquid nitro- gen, following the procedures for liquid cooling in ASTM Standard E 23-B8.

\section{Metallographic Examination}

The NIST welds were sectioned transverse to the welding direction and prepared using standard grinding and polishing techniques for metallographic examination. The two-dimensional (2-D) inclusion volume fraction and size distribution were determined hy scanning electron microscopy in combination with automatic image analysis at a magnification of $2500 \mathrm{X}$, using polished specimens. A total of 500 particles were counted for cach specimen.

\section{Test Results}

\section{Inclusion Characteristics}

The measured 2-D inclusion diameters and the number of inclusions per unit arca are shown in Table 5 and compared with the oxygen content for the test welds. The data were developed at NIST using the heat it had purchased. The inclusion density for the welds has a direct relationship with oxygen content, with a $25 \%$ reduction in oxygen content producing a $36 \%$ reduction in inclusion density, and a $50 \%$ reduction in oxygen content producing a $50 \%$ reduction in inclusion density. Most significant in this study is that inclusion density remained directly proportional to the oxygen content for a given set of welding procedures. Oxygen content can be obtained more quickly and easily than inclusion density or Charpy data, with techniques less prone to errors. Thus, relating the desired fracture toughness to oxygen content would be a desirable future goal, but requires validation for a wider range of materials and processes. 


\section{Weld Metal Tensile Properties}

The results of the tensile testing at $4 \mathrm{~K}$ are summarized in Table 6 . The $0.2 \%$ offset yield strength ranged from 868 to $995 \mathrm{MPa}$, and the ultimate tensile strength ranged from 1222 to $1412 \mathrm{MPa}$. In addition, a minimum value of $26 \%$ has been obtained for total elongation and $24 \%$ for reduction of area. All specimens broke in the weld and in the gauge length. The reduction in area data for one weld is unavailable.

\section{Weld Metal Toughness}

The fracture toughness results ranged from 218 to $286 \mathrm{MPa} \cdot \mathrm{m}$ and are listed in Table 7. The welds were quite ductile and sn did not meet all the criteria of a $K_{1}$ test. Therefore, the results are listed as $\mathrm{K}_{\mathrm{Q}} \mathrm{re}$ sults. These results are discussed elsewhere, but the conclusions are that the weld metal's fracture properties decrease with increasing inclusion volume fraction and that the inclusion volume fraction is proportional to the weid metal oxygen content up to about $0.08 \%$ (Ref. 21). For this study, Charpy V-notch testing was conducted at three temperatures, with the results shown in Table 8 . CVN energies at $76 \mathrm{~K}$ ranged from 136 to $174 \mathrm{I}$, and room temperature energies from 193 to 243 \%. CVN energies increased an average of 25 I with a $25 \%$ reduction in oxygen content or a $36 \%$ reduction in inclusion density. The results also are plotted in Fig. 7 .

The plot shows that impact energy is directly affected by oxygen contenl and inclusion density, with that effect consistent throughnut the temperature range lested. Also notable is the increase in data scatter at warmer temperatures.

Lateral expansion increased with oxygen content and inclusion density, contradicting the decrease in impact energy, but consistently decreased with temperature - Fig. 8. Lateral expansion ranged from 1.15 to $1.64 \mathrm{~mm}$ at $76 \mathrm{~K}$ and at ronm temperature from 1.45 to $2.39 \mathrm{~mm}$. Lateral expansion decreased an average of $26 \%$ with a $25 \%$ reduction in oxygen content, or with a $36 \%$ reduction in inclusion density. The data in Fig. 8 also show increased scatter with increased oxygen content and a sharper decline in lateral expansion at lower temperatures with increased oxygen content.

The fractographic examinations revealed all the welds failed in a ductile manner, with fracture surfaces exhibiting typical ductile dimple morphologies on a microscale, as shown by Figs. 9 and 10 . These fractographs also show that the dimple diameter is inversely related to inclusion content. This observation is consistent with previous findings (Refs. 21, 22).

Table 5 - Inclusion Size Distribution and Density

\begin{tabular}{llccc} 
Alloymeld & Shielding Gas & $\begin{array}{c}\mathrm{O}_{2} \text { Content } \\
(\text { wt- } \%)\end{array}$ & $\begin{array}{c}\text { Density } \\
\left(\pi \times 10^{2} / \mathrm{mm}^{2}\right)\end{array}$ & $\begin{array}{c}\text { Mean Diameter. } \\
(\mu \mathrm{m})\end{array}$ \\
NI5T/NI5T & $\mathrm{Ar}$ & 0.012 & 2.21 & 0.35 \\
NIST/NIST & $\mathrm{Ar} / 0.5 \% \mathrm{O}_{2}$ & 0.023 & 4.80 & 0.33 \\
NI5T/NIST & $\mathrm{Ar} / 2 \% \mathrm{O}_{2}$ & 0.046 & 8.46 & 0.35 \\
\hline
\end{tabular}

Table 6 - Weld Metal Tensile Properties (4 K)

\begin{tabular}{|c|c|c|c|c|c|}
\hline Alloy Weld & Shielding Gas & $\begin{array}{c}\text { Sy } \\
(\mathrm{MPa})\end{array}$ & $\begin{array}{c}\mathrm{Su} \\
(\mathrm{MPa})\end{array}$ & $\begin{array}{c}\text { Elongation } \\
(\%)\end{array}$ & $\begin{array}{c}\text { Reduction of } \\
\text { Area }(\$ \% s)\end{array}$ \\
\hline NIST/NIST & $\mathrm{Ar}$ & 995 & 1340 & 49 & 42 \\
\hline NIST/NIST & $\mathrm{Ar} / 0.51 / \% \mathrm{O}_{2}$ & 975 & 1220 & 26 & 24 \\
\hline NIST/NIST & $\mathrm{Ar} / 2 \% \mathrm{O}_{2}$ & 940 & 1270 & 39 & 27 \\
\hline NIST/BNL & $\mathrm{Ar}$ & 875 & 1320 & 41 & NA \\
\hline BNL/BNL & $\mathrm{Ar} / 1 \% \mathrm{CO}_{2}$ & 870 & $1+10$ & 31 & 27 \\
\hline
\end{tabular}

Table 7 - Weld Metal Fracture Toughness (4 K)

\begin{tabular}{|c|c|c|c|c|}
\hline Alloy Weld & Shielding Gas & $\begin{array}{c}\mathrm{O}_{2} \\
(\mathrm{Wt}-\% / \mathrm{s})\end{array}$ & $\begin{array}{c}\text { Inclusion Density } \\
\left(4 \times 10^{3} / \mathrm{mm}^{2}\right)\end{array}$ & $\frac{\mathrm{K}_{\mathrm{Q}}}{(\mathrm{MPaV} / \mathrm{m})}$ \\
\hline NIST/NIST & $\mathrm{Ar}$ & 0.012 & 2.21 & 272 \\
\hline NIST/NIST & $\mathrm{Ar} / 0.5 \% \mathrm{O}_{2}$ & 0.023 & 4.80 & 286 \\
\hline NIST/NIST & $\mathrm{Ar} / 2 \% \mathrm{O}$ & 0.046 & 8.46 & 218 \\
\hline
\end{tabular}

Table 8 - Weld Metal Charpy Test Results

\begin{tabular}{lccccccc} 
& & \multicolumn{2}{c}{$295 \mathrm{~K}$} & \multicolumn{2}{c}{$185 \mathrm{~K}$} & \multicolumn{2}{c}{$76 \mathrm{~K}$} \\
Alloy & $\mathrm{O}_{1}(\%)$ & CVN (j) & LE (mm) & CVN (j) & LE (mm) & CVN (j) & LE (mm) \\
NIST & 0.024 & 209 & 2.23 & 176 & 2.14 & 139 & 1.53 \\
BNL & 0.018 & 229 & 1.56 & 206 & 1.52 & 166 & 1.22 \\
\hline
\end{tabular}

\section{Ferrite}

The alloy is fully austenitic, that is, the FN measurements are consistently less than 0.1. From the WRC-1992 diagram, the tested alloys have a nickel equivalent of 29.5 (BNL alloy) and 29.8, with a chromium equivalent of 26.2-26.5, yielding a ferrite potential of -5.6 to -5.4 . Yet there have been no instances of hot cracking (during the visual inspection of completed weld surfaces or on cross sections produced during procedure development) in more than $1000 \mathrm{~kg}$ of weld metal deposited to date. This can be attributed to the very low levels of phosphorous and sulfur, which were specified as a precautionary measure. Kujanpaa, et al. (Ref. 13), have found that susceptibility to hot cracking exists when the sum of the weights of phosphorous and sulfur exceeds $0.01 \%$, but is almost eliminated with a chromium equivalent/nickel equivalent $\left([\mathrm{Cr} / \mathrm{Ni}]_{\text {pel }}\right.$ ) ratio greater than 1.48 . In this study, the sum of the weights of phosphorous and sulfur is at least $0.015 \%$, but the $(\mathrm{Cr} / \mathrm{Ni}\rangle_{\mathrm{eq}}$ is 0.89 , yet we see no cracking. It is possible that additions of manganese and copper beyond those of Ref. 13 may modify the interdendritic regions and so reduce the cracking tendency.
Weldability

Weldability is a significant concern, especially in a production environment, and shielding gas has a major role. Manual GTAW with 100\% argnn had good welder appeal, bead appearance and pool control. Manual GMAW when using $100 \%$ argon scored poorly in welder appeal, bead appearance, pool control and wetting action. Automatic pulsed GMAW was impossible using $100 \%$ argon due to arc instability. All categories of weldability improved when $1 \% \mathrm{CO}_{2}$ was added to the shielding gas mixture, although further improvement in wetting action is desirable. Mixtures of hydrogen and helium are recommended for this type of application, and preliminary testing showed marked improvement in GTA weldability with the addition of hydrogen to the shielding gas with no effect on mechanical properties.

In summary, this new alloy has an excellent combination of both strength and toughness, while maintaing acceplable weldability. Figure 11 shows how well the weld strength and toughness combination (the data from Tables 6 and 7) matches that of Type 304 base metal, while substantially exceeding the properties of the Type 
308 and 316 weld compositions usually specified for this application.

\section{Conclusions}

A high-nickel/high-nitrogen superaustenitic weld alloy provides exceptional mechanical properties for $4 \mathrm{~K}$ cryogenic welded structures using production-welding processes.

Oxygen content has a direct effect on inclusion density, fracture toughness and CVN energy. Weld metal oxygen analysis can serve as a convenient quality assurance tool to help predict toughness.

Size distribution and density of inclu. sions have a direct and significant effect upon weld metal tracture toughness. However, a procedure for determining inclusion density must be standardized before this can be used to predict fracture toughness.

Hot cracking has not been experienced with this superaustenitic weld alloy. This may be attributed to the low contents of phosphorus and sulfur in the test alloys, but hot cracking susceptibility for stainless steels with $(\mathrm{Cr} / \mathrm{Ni})_{\mathrm{eq}}$ ratio less than 1 needs additional investigation.

Adequate weldability was achieved with the addition of $1 \% \mathrm{CO}_{2}$ to the shielding gas and this addition did not adversely affect cryogenic material properties.

\section{References}

1. Tobler, R. L., Reed, R. P., Hwang, I. S., Morra, M. M., Ballinger, R. G., Nakajima, H., and Shimamoto, S. 1991. Charpy impact tests near absolute zero. Journal of Testing and Evalwation 19(1): 34

2. Tobler, R. L., Siewert, T. A., and McHenry, H. I. 1986. Strength-toughness relationship of austenitic stainless steel welds at 4 K. Cryogenics 26: 392.

3. Goodwin, G. 1985. Welding process selection for fabrication of a superconducting magnet struclure. Welding fournal 64(8): 19.

4. Dalder, E. N. C., Seth, O. W., and Whipple, T. A. 1981. Evaluation of shielded metal arc and filux cored metal arc welding consumables for fabrication of stainless steel magnet cases for $4 \mathrm{~K}$ service. International Cryogenic Materials Conference, San Diego, Calif, August 10-14.

S. Reed, D. T., McHenry, H. I., Steinmeyer, P. A., and Thomas, Jr., R. D. 1980 . Metallurgical factors affecting the toughness of $316 \mathrm{~L}$ SMA weldments at cryogenic temperatures. Welding fournal 59(4): 104-s.

6. Kim, J. H., Oh, B. W., Youn, J. G., Bahng, G., and Lee, H. 1990. Effect of oxygen content on cryogenic toughness of austenitic slainless steel weld metal. Advances in Cryogenic Engineering (Materials) 368: 1339.

7. Siewert, T. A., and McCowan, C. N. 1992. Joining of austenitic stainless steels for cryogenic applications. Advances in Cryogenic Engineering (Materials) 388: 109.

8. McCowan, C. N., Siewert, T. A. Reed, R. P., and Lake, F. B. 1987. Manganese and nitrogen in stainless steel SMA welds for cryogenic service. Welding fournal 66(3): 84-5.

9. Siewert, T. A. 1978. How to predict impact energy from stainless steel weld composition. Welding Design \& Fabrication (June): 88.

10. Szumachowski, E. R. and Reid, H. F. 197B. Cryogenic toughness of SMA austenitic stainless steel weld metals: Part I - Role of ferrite. Welding fournal 57(11): 325-s.

11. Szumachowski, E. R., and Reid, H. F, 1979. Cryogenic toughness of SMA austenitic stainless steel weld metals: Part li - Role of nitrogen. Welding lournal 58(2): 34-s.

12. Siewert, T. A., and McCowan, C. N. 1990. Cryogenic mechanical property data for $20 \mathrm{Cr}-25 \mathrm{Ni}-4.5 \mathrm{Mo}$ gas metal arc welds. Materials Studies for Magnetic Fusion Energy Applications at Low Temperatures - XIII, NISTIR 3944 National Institute of Slandards and Technology, p. 233.

13. Kujanpaa, V., Suutala, N., Takalo, T., and Moisio, T. 1979. Correlation between 50lidification cracking and microstructure in austenitic and austenitic-ferritic stainless steel welds. Welding Research Internationa/ 9(2): 55.

14. Simon, N. J., and Reed, R. P. 1986. Strength and toughness of AISI 304 and 316 at $4 \mathrm{~K}$. Journal of Nuclear Materials, Vol. 141-3: 44.

15. McCowan, C. N., and Siewert, T. A. 1988. Inclusions and fracture toughness in stainless steel welds at $4 \mathrm{~K}$. Advances in Cryogenic Engineering (Materials) 34B: 335.

16. ASME Boiler and Pressure Vessel Code, Section II, SFA 5.4, A8, and SFA 5.9, A6.

17. Whipple, T. A., and Kotecki, D. I. 1981. Weld process study for $316 \mathrm{~L}$ stainless steel weld metal for liquid helium service. Materials Studies for Magnetic Fusion Energy Applications at Low Temperatures - IV, NBSIR 811645. National Bureau of Standards, Boulder, Colo., p. 303.

18. McCowan, C. N., and Siewert, T. A. 1990. Fracture toughness of $316 \mathrm{~L}$ stainless steel weids with varying inclusion contents at $4 \mathrm{~K}$. Advances in Cryogenic Engineering ( $\mathrm{Ma}$ terials) 36B: 1331.

19. Brookhaven National Laboratory. Feb. 16, 1993. Weld filler metal for RHIC magnets. RHIC Magnet Division Specification, RHICMAG-M-4360.

20. Siewert, T. A., Gorni, D., and Kohn, G. 1988. High-energy-beam welding of Type $316 \mathrm{LN}$ stainless steel for cryogenic applications. Advances in Cryogenic Engineering (Materials) 348: 343.

21. Siewert, T. A., and McCowan, C. N. 1987. Welding metallurgy of structural steels. Proceedings Internationa/ TMS/EWI Symposium, Denver. Ed. J.Y. Koo, Warrendale, Pa., p. 415.

22. Kluken, A. O., Grong, $\ddot{y}_{.}$, and Hjelen, 1. 1988. SEM based automatic image analysis of non-metallic inclusions in steel weld metals. Materials Science and Technology Vol. 4 , No. 7: 649 .

\section{REPRINTS REPRINTS}

To Order Custom Reprints of Articles in the

Welding Jouranl

Call Denis Mulligan

at (800) 259-0470 